\title{
Dynamic orthoses for the management of microstomia
}

\author{
TALI A. CONINE, Dr. H. Sc., P.T.;* DEBORAH L. CARLOW, B.S.R.; PETER STEVENSON- \\ MOORE, B.D.S., M.S.D., L.D.S., R.C.C., M.R.C.D.(C) \\ Vancouver General Hospital, University of British Columbia, and the Cancer Control Agency of British Columbia, \\ Vancouver, British Columbia, Canada
}

\begin{abstract}
Oral wounds and burns may result in microstomia with significant management problems. An important early management decision involves the selection of an appliance capable of applying forces that will halt and reverse the condition. A selection appropriate to the patient may be based on the need for teeth suitably placed to retain and position a particular device. Limited access to the patient's mouth because of recent trauma, surgery, wiring, inability to tolerate anesthetic, etc., may further restrict choices. Thus, the process of selection involves a weighing of the specific patient's condition and program of treatment against an understanding of the unique features, including complexity of fabrication and durability, of the range of prostheses available. This article provides an overview of the structural and clinical characteristics of seven dynamic intraoral and extraoral microstomia appliances. The need for interdisciplinary management of microstomia with appliances has been noted, and opportunities for research have been pointed out.

DOI $10.1682 / J R R D .1987 .07 .0043$
\end{abstract}

\section{INTRODUCTION}

Microstomia is a reduction in the size of oral aperture associated with facial burns, diffuse scleroderma, traumatic injuries, and surgical reconstruction involving the orbicularis oris muscle. It can result in multiple debilitating sequelae, such as inability to masticate, drooling, speech problems due to poor articulation, impaired delivery of oral

\footnotetext{
*Address correspondence to: Tali A. Conine, Dr.H.Sc., P.T.; Professor of Rehabilitation Medicine; University of British Columbia; Vancouver, B.C. V6T 1W5, Canada.
}

hygiene and dental care, and psychological problems secondary to facial disfigurement $(3,8,11,13)$.

In the preceding article we presented information about eight tissue-borne and four tooth-borne static orthoses used in the management of microstomia (1). The structural and clinical features of each were described to facilitate the interdisciplinary participation of health professionals in the selection of the most suitable appliance for the individual patient. The purpose of this article is to provide an overview of dynamic microstomia orthoses.

All microstomia orthoses use the concepts applied in prosthodontics by providing external distracting forces to prevent or correct oral and dental deformities, as in the correction of cleft lips and cleft palate and malocclusion. For the management of microstomia, the specific purpose is to apply forces to maintain the symmetry of oral stoma by positioning each commissure equidistant from the midline of the lips, and by stabilizing the orbicularis muscle at a two-point fixation. Dynamic microstomia orthoses provide the external forces either intraorally or extraorally. Their general advantage over static appliances is that the pressure exerted by the device is adjustable and will permit progressive controlled tension. Alterations to dynamic orthoses do not require basic structural changes to the appliance.

\section{DYNAMIC ORTHOSES}

Sansplint $\mathrm{XR}^{\circledR}$ is the registered trademark for a 
mercially available through Smith \& Nephew Inc. (15). It is used by therapists in the fabrication of a dynamic microstomia orthosis, according to specific directions provided by Smith \& Nephew (5). The material is heated until it becomes uniformly malleable to form a negative mold of the corners of the mouth (commissures). A pair of hook-shaped Kirschner wires wrapped in two small pieces of the Sansplint XR are secured between the two commissural portions in a parallel position and allowed to slide over one another (Figure 1). Orthodontic elastics are placed between the wires' hooks to supply the required pressure against the commissures. The diameter and number of elastics will determine the amount of force applied.

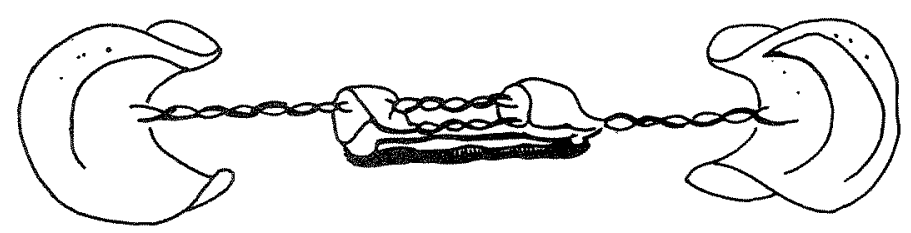

Figure 1.

Sansplint $X-R$ composed of two commissural posts, connected by sliding wires pulled by orthodontic elastics.

This is a relatively inexpensive appliance in terms of the materials used. However, its fabrication is complex and the presence of wires which pass across the oral opening present difficulties for the user in speaking and eating.

The fabrication of the Lip-Expander (Figure 2), an intraoral appliance, has been described in detail by Jackson (9). It requires that an impression of the maxillary and mandibular arches be taken, incorporating the occlusal and lingual surface of the teeth, palate, and commissures. The impressions are poured in dental stone to make casts. A hard-acrylic biteplate palatal appliance is constructed similar to those employed for temporomandibular dysfunction. Acrylic blocks encompassing the external and internal curvatures of the commissures are reproduced from the casts. A groove is placed in the middle of these blocks for the retention of two 18-gauge wires, which are fastened with acrylic resin. A hook is placed at the end of each wire for the attachment of rubber bands to push the two commissure blocks outward. The Lip-Expander derives its retention from embracing the buccal and lingual surfaces of the maxillary teeth and embrasures.

The Lip-Expander is easy to place, use, and care for. It can be retained day and night fairly comfortably, and can be removed for eating. A disadvantage of this device is that its fabrication for young children requires a general anesthetic for taking a mold of the maxillary and mandibular arches. The insertion of suitable impression trays when taking the mold may be difficult when the oral opening is severely restricted.

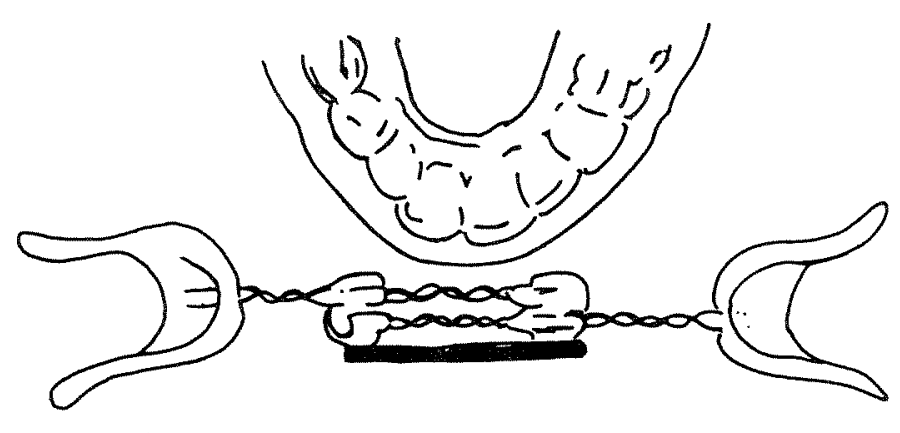

Figure 2.

Lip-Expander made of a palatal portion and two acrylic commissure blocks held by wire and attached to rubber bands.

The Microstomia Prevention Appliance ${ }^{\circledR}$ or "MPA" was described in the article on static appliances $(7,12)$. Although it is commonly used as a static source of force, it may be adapted as a dynamic device. This is accomplished by loosening the set screw and placing orthodontic elastics in the grooves (Figure 3). The diameter and number of the elastics determines the amount of pressure applied against the commissures.

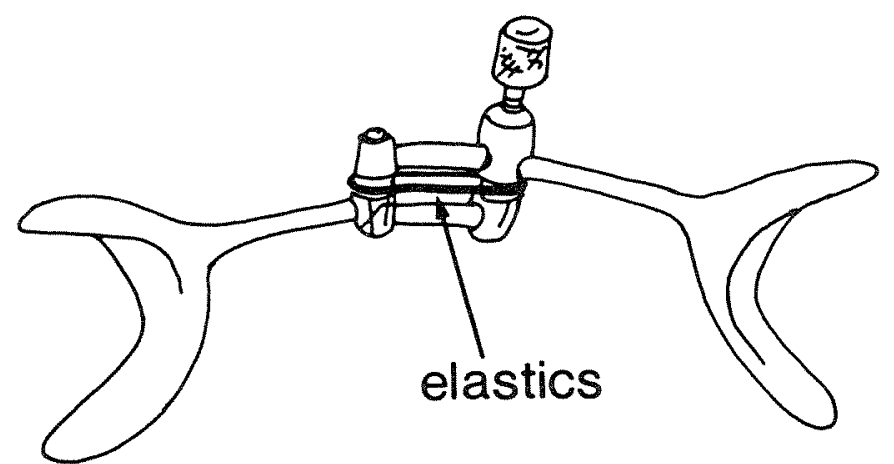

Figure 3.

Microstomia Prevention Appliance used as a dynamic device when the screws are loosened and orthodontic elastics are placed in the grooves. 
As in the case of the intraoral orthosis, the MPA's metal bar spanning the oral opening interferes with speech. For eating and drinking, the device must be removed. It is not suitable for young children, or when circumferential force to the lips must be sustained (6). The decided advantage of this appliance is its commercial availability and ease of application.

The Circumoral Retractor (Figure 4) is a large and somewhat bulky orthosis constructed from two photographic cheek retractors mounted on an acrylic resin frame (11). Screws are placed through slots in the retractors. Elastic bands of various sizes are used over the screws to produce a dynamic force against the tissues.

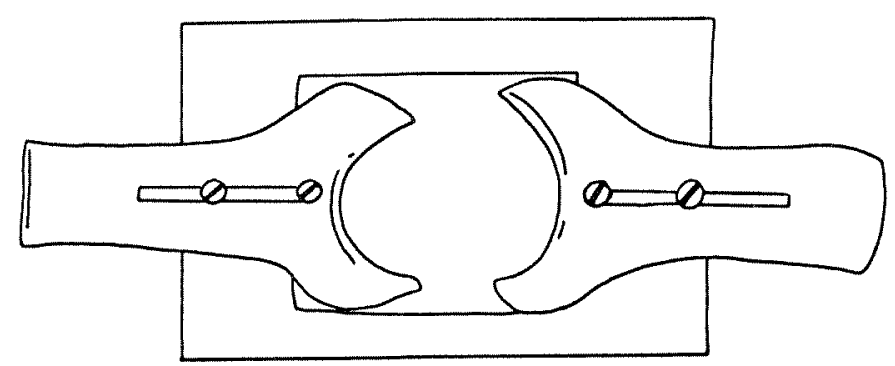

Figure 4.

Circumoral Retractor using two photographic cheek retractors mounted on an acrylic frame.

The advantage of this device is its relative ease of fabrication and adjustment. The main application is for circumoral burns.

The Dynamic Microstomia Prevention Splint (Figure 5) is an extraoral device developed at the University of Chicago, and the method of its fabrication has been fully described (14). An impression of the involved commissure is taken, using softened wax. The wax is chilled and carved to form the final pattern for a silicone mold. Acrylic resin is placed in this mold and cured under pressure to make the commissure conformer for the splint. A wire processed into a channel in the conformer is bent at the end for the attachment of a neck strap. The neck strap can be adjusted to alter the pressure applied at the commissure.

According to Reisberg, et al. (14) the silicone mold permits easy retrieval of the conformer and may be reused numerous times to fabricate new conformers for other patients. Thus, it eliminates the costly need for custom appliance fabrication.

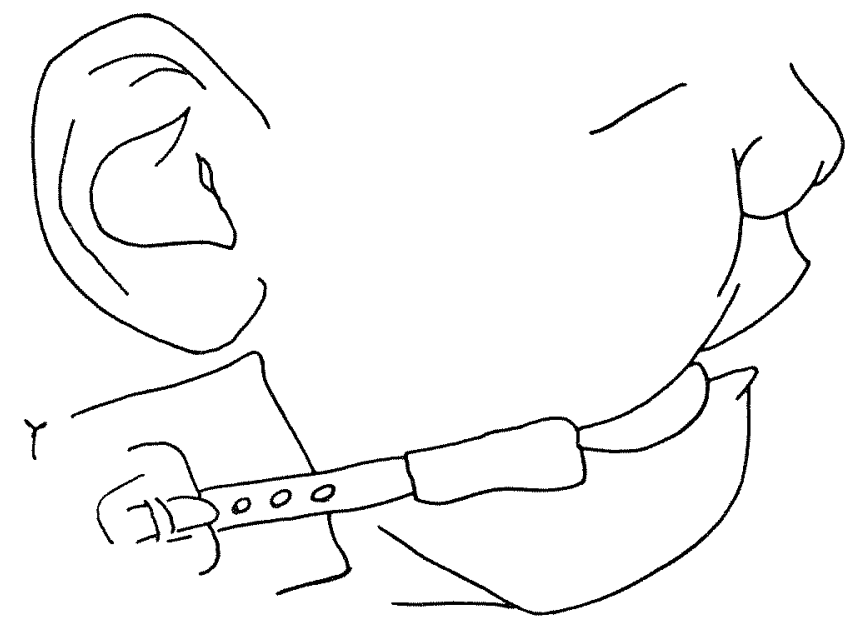

Figure 5.

Dynamic Microstomia Prevention Splint offers pressure to commissural conformers through an elastic neck strap.

The shortcoming of this orthosis is that, although the neck strap is adjustable, the acrylic conformer is not flexible (10). In addition, it cannot be used if the injury involves the face and neck area at points where the strap of the appliance must contact the skin.

A variation of the above splint is the Occipitally Supported Appliance (Figure 6), which is fabricated from an orthodontic directional force headgear. The

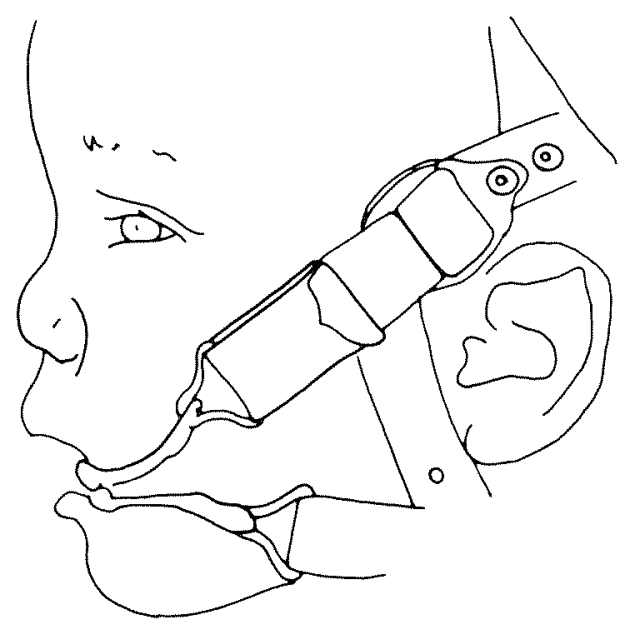

Figure 6.

Occipitally Supported Appliance offers retraction to the commissures in the horizontal and vertical directions with oral functions. 
Journal of Rehabilitation Research and Development Vol. 24 No. 3 Summer 1987

faceplate is centered with the ear and attached to four heavy elastic straps (10). Bilateral commissural wire loops covered with IV tubing are connected to the straps. Adjustments to the straps and wires offer the necessary retraction and allow regulation of the amount and direction of forces applied to the commissures.

Josell has described case reports that indicate this appliance is well tolerated by children and to be beneficial in preventing scar formation (10). It can be prefabricated, and is easily adjusted and maintained. Moreover, with this device in place, the patient can eat, drink, and speak.

A frequently cited 1976 article by B. G. Denton and $\mathrm{S}$. E. Shaw is one of the earliest reports of the use of a microstomia appliance for controlling hypertrophic scarring around the exterior of the mouth (4). The orthosis, called the Mouth Conformer (Figure 7), consists of oral commissure retractors with circumcranial traction. Low-temperature thermoplastic material is used to cut out and shape the conformer to the corners of the mouth. Elastic straps, riveted to the exterior portion of the mouthpiece, provide the tension which can be adjusted easily.

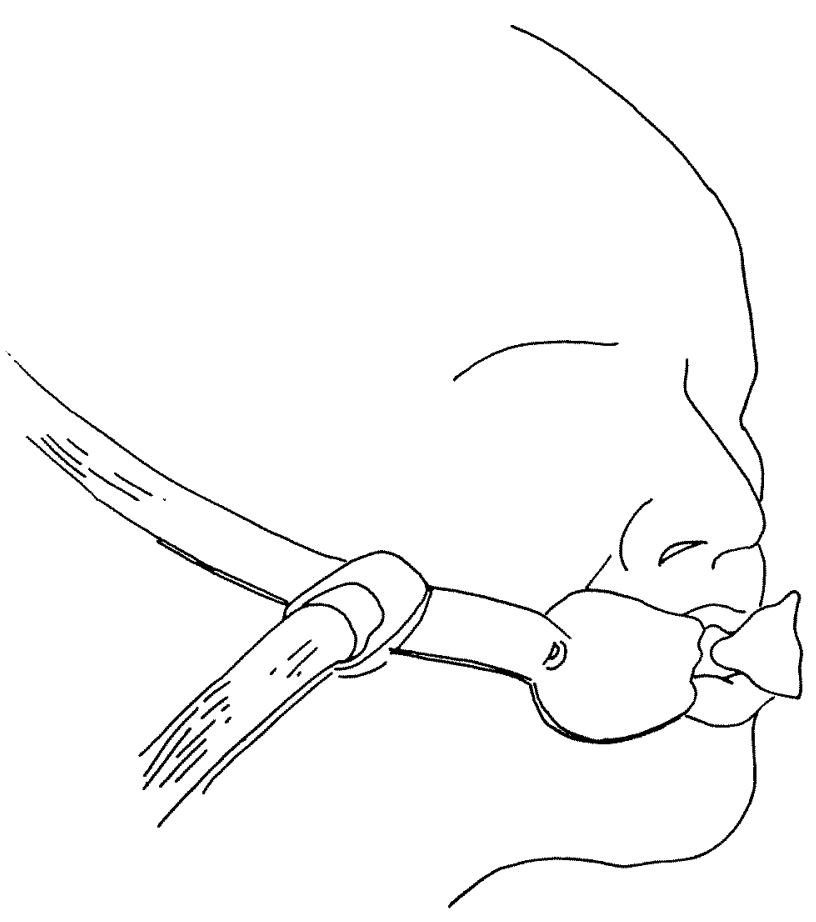

Figure 7.

Mouth Conformer provides traction to shaped thermoplastic commissural pieces.
The mouth conformer is economical, is readily fabricated, and is easily applied by the patient. It is well tolerated by children. The major limitation of this device, as of the two described above using neck or head gear, is the contraindication when open wounds exist in the area of cheeks, ears, neck, face, or occiput as the straps may contact the injured skin.

\section{DISCUSSION}

In this article we have reviewed the important structural and clinical features of seven major dynamic appliances for microstomia that have been used and reported to be beneficial. Table 1 summarizes some of the salient points for ease of reference by the reader.

Splinting of oral wounds and burns may present significant management problems. Most intraoral devices, such as those described in this and the previous article, rely on the dentition for retention. The displacement forces exerted within the mouth by lips, cheeks, and tongue, may necessitate frequent readjustments. If the devices are removable, patient compliance may be a problem. Extraoral orthoses also may present difficulties as they are bulky and may limit access to the oral cavity (e.g., for eating) when the appliance is in place. The circumoral types (e.g., those with neck or head straps) eliminate the connecting bars that run across the mouth and are appropriate for young children with few or no teeth, but do not apply differential pressure for maintaining ideal positioning of the affected commissure (2).

An important consideration in the selection of a microstomia orthosis is that the device must be worn continuously for a 6 to 12 month period. Therefore, the suitability of each appliance must be assessed on the basis of an estimate of the patient's compliance; and the factors of safety, comfort, durability, expense and need of repair; complexity of fabrication; and frequency of followup and readjustment. Arriving at a reasonable decision would be facilitated if the clinical management of microstomia were planned jointly by the physicians, dentists, therapists, and other health professionals who are familiar with the significant variables affecting the efficacy and effectiveness of the appliances. 
Table 1

Major structural and clinical features of dynamic intraoral and extraoral microstomia orthoses

\begin{tabular}{|c|c|c|c|c|c|c|c|c|c|}
\hline \multirow{2}{*}{ Orthosis } & \multirow{2}{*}{ Major Materials } & \multirow[t]{2}{*}{$\begin{array}{l}\text { Alginate } \\
\text { Mold } \\
\text { Required }\end{array}$} & \multicolumn{4}{|c|}{ Area Pressure Applied } & \multicolumn{3}{|c|}{ Appropriate Age } \\
\hline & & & $\begin{array}{c}\text { Circum- } \\
\text { Oral } \\
\end{array}$ & $\begin{array}{l}\text { Commis- } \\
\text { sure }\end{array}$ & Horizontal & Vertical & Adults & $\begin{array}{l}\text { Older } \\
\text { Child }\end{array}$ & $\begin{array}{l}\text { Young } \\
\text { Child } \\
(2 \mathrm{yr} .) \\
\end{array}$ \\
\hline $\begin{array}{l}\text { Sansplint } \\
X-R \text { Splint } B\end{array}$ & $\begin{array}{l}\text { Thermoplastic } \\
\text { Kirschner wires, } \\
\text { orthodontic } \\
\text { elastics }\end{array}$ & No & & $\mathrm{X}$ & $x$ & & $\mathrm{X}$ & $\mathrm{x}$ & \\
\hline Lip-Expander & $\begin{array}{l}\text { Acrylic, wires, } \\
\text { rubber bands }\end{array}$ & Yes & & $\mathrm{X}$ & $\mathrm{X}$ & & $\mathrm{X}$ & $x$ & $\mathrm{x}$ \\
\hline $\begin{array}{l}\text { Microstomia } \\
\text { Prevention } \\
\text { Appliance }\end{array}$ & $\begin{array}{l}\text { Acrylic, metal } \\
\text { bars, orthodontic } \\
\text { elastics }\end{array}$ & No & & $\mathrm{x}$ & $\mathrm{X}$ & & $\mathrm{x}$ & $\mathrm{X}$ & \\
\hline $\begin{array}{l}\text { Circumoral } \\
\text { Retractor }\end{array}$ & $\begin{array}{l}\text { Two lip and cheek } \\
\text { retractors, acrylic } \\
\text { resin frame, rub- } \\
\text { ber bands }\end{array}$ & No & $\mathrm{X}$ & & $\mathrm{X}$ & & $\mathrm{X}$ & $x$ & \\
\hline $\begin{array}{l}\text { Dynamic } \\
\text { Microstomia } \\
\text { Prevention } \\
\text { Splint }\end{array}$ & $\begin{array}{l}\text { Acrylic, elastic } \\
\text { neck strap }\end{array}$ & No & & $\mathrm{X}$ & $\mathrm{X}$ & & $\mathrm{X}$ & $x$ & $x$ \\
\hline $\begin{array}{l}\text { Occipitally } \\
\text { Supported } \\
\text { Appliance } \\
\end{array}$ & $\begin{array}{l}\text { Wire, IV tubing, } \\
\text { orthodontic head- } \\
\text { gear }\end{array}$ & No & & $\mathrm{X}$ & $\mathrm{X}$ & & $\mathrm{X}$ & $\mathrm{x}$ & $x$ \\
\hline $\begin{array}{l}\text { Mouth } \\
\text { Conformer }\end{array}$ & $\begin{array}{l}\text { Thermoplastic, } \\
\text { elastic straps }\end{array}$ & No & & $\mathrm{X}$ & $\mathrm{X}$ & & $\mathrm{x}$ & $x$ & $\mathrm{X}$ \\
\hline
\end{tabular}

Our extensive search of the literature related to microstomia revealed published descriptions of a large variety of appliances. Some included case reports or limited retrospective analyses involving small numbers of subjects. It seems that research projects are needed to investigate the relative clinical efficacy of these devices based on prospective randomized controlled trials or well formulated singlesubject designs. Data collection and analysis are also needed to determine the most beneficial force direction, amount of traction, and the timing for application of traction (14).

\section{Acknowledgement}

The authors thank Ms. Jean Stephens, Director of Occupational Therapy, Vancouver General Hospital, for her assistance and encouragement in the development of this manuscript; and, the Department of Medical Illustrations of the Cancer Control Agency of British Columbia for the preparation of the illustrations. 
Journal of Rehabilitation Research and Development Vol. 24 No. 3 Summer 1987

\section{REFERENCES}

1. Carlow DL, Conine TA, Stevenson-Moore P: Static orthoses for the management of microstomia. $J$ Rehabil Res Dev 24(3), 35-42, 1987.

2. CZEREPAK CS: Oral splint therapy to manage electrical burns of the mouth in children. Clin Plast Surg 11:682$685,1984$.

3. DAHL E AND Fogh-ANDERSEN P: Electric burns of the mouth, long-term effects on the dentition: Surgical and orthodontic considerations. Europ J Orthodont 2:207-217, 1980.

4. DEnTon BG AND SHAw SE: Mouth conformer for prevention and correction of burn scar contracture. Phys Ther 56:6:683-686, 1976.

5. Fabrication of a Microstomia Splint with Sansplint XR (Ref H10). Lachine, Quebec: Smith \& Nephew Inc. (Not dated.)

6. GAY WD: Prostheses for oral burn patients. J Prosthet Dent 52:4:464-566, 1984.

7. Hartford CE, Kealey GP, Lavelle WG, Buckner H: An appliance to prevent and treat microstomia from burns. J Trauma 15:356-361, 1975.
8. Holt GR, Parel S, Richardson DS, Kittle PE: The prosthetic management of oral commissure burns. Laryngoscope 92:407-411, 1982.

9. JACKSON MJ: The use of a dynamic lip-expander in the rehabilitation of a severely burned face: Report of a case. $J$ Dent Child 66:230-233, 1979.

10. Josell SD, Owen D, Kreutzer LW, Goldberg, NH: Extraoral management for electrical burns of the mouth. $J$ Dent Child 51:1:47-52, 1984.

11. LEAKE JE AND CURTIN JW: Electrical burns of the mouth in children. Clin Plast Surg 11:669-683, 1984.

12. Microstomia Prevention Appliance, 13720 Hillcrest Road, Dallas, Texas 75240.

13. Parel SM: Scleroderma: A prosthetic problem. $J$ Prosthet Dent 27:560-564, 1972.

14. Reisberg DJ, Fine L, Fattore L, Edmonds DC: Electrical burns of the oral commissure. $J$ Prosthet Dent 49:1:71-76, 1983

15. Smith \& Nephew, Inc., 2100-52 Avenue, Lachine, Quebec H8T 2Y5, Canada. 